\title{
Introduction to the Special Issue: Select Papers Presented at the 2019 OLC Accelerate Conference and the 2020 OLC Innovate Conference
}

\author{
Patsy D. Moskal \\ University of Central Florida \\ Laurie Dringus \\ Nova Southeastern University \\ Paige McDonald \\ George Washington University \\ Karen Swan \\ University of Illinois Springfield
}

We are happy to present five articles selected from the many presented at OLC Accelerate, held November 19-22, 2019 in Orlando, Florida, and OLC Innovate, moved from Chicago to a virtual conference June 15-26, 2020. We invite the readers to consider presenting their research to OLC conferences in the future.

The Online Learning Consortium (OLC) sponsors two annual conferences devoted to furthering the OLC mission of creating community and knowledge around quality online, blended, and digital learning while driving innovation. These conferences are known as premiere conferences for faculty, instructional designers, administrators and others who teach or support those who teach in online and blended learning.

The 2019 OLC Accelerate conference marked the $25^{\text {th }}$ anniversary of this international conference. The event was held November 19-22 in Orlando, Florida's Walt Disney World Dolphin and Swan Resort with 1,623 onsite and over 1,000 virtual attendees from 13 countries, 49 states, Washington, D.C. and Puerto Rico.

Little did we know that 2020 would bring new adventures and challenges! OLC Innovate, originally scheduled for March 31-April 3, 2020 was postponed and reimagined after COVID-19 forced its Chicago venue to close. With a quick pivot and fantastic planning by the OLC team, the conference went virtual June 15-26 with 370 presenters and contributors and 5,500+ attendees from nearly 500 organizations/institutions, representing 35 countries, all 50 states, Washington D.C. and Puerto Rico.

Each year we highlight articles from a selected few presentations from these conferences for publication in Online Learning. The five selections here represent a variety of topics from varied institutions of higher education. 
In "Relationships Between Carl Rogers' Person-Centered Education and the Community of Inquiry Framework: A Preliminary Exploration," Karen Swan, Cheng-Chia (Brian) Chen, and Denise Bockmier-Sommers, investigated connections between Rogers' core conditions (empathy, genuineness, and unconditional positive regard) and the Community of Inquiry (CoI) framework of three "presences" supporting learning: teaching presence, social presence, and cognitive presence. Using the Berrett-Lennard Relationship Inventory (BLRI) and Community of Inquiry Survey $(\mathrm{CoI})$ they conducted preliminary survey research using online students at a small, Midwestern university. Results indicated significant connections between level of regard, empathy and CoI presences, especially teaching presence. The authors discuss future research and practical applications of their findings for online teaching.

Tara Lehan, Bethanne Shriner and Michael Shriner looked at the relationship between synchronous, one-on-one academic coaching and students' program completion in 'It's Complicated: The Relationship Between Participation in Academic Coaching and Program Completion in Online Graduate Students." Building on their prior research that had indicated a correlation between academic coaching and student persistence, they compared a random sample of students who participated in academic coaching to a matched sample of students who did not receive academic coaching in a fully online graduate course. While a relationship was found between some demographic variables and program completion, no significant difference was found between those who received coaching and those who did not. They discuss limitations to their study and possible implications for future research.

In "Procrastination and Delayed Assignment Submissions: Student and Faculty Perceptions of Late Point Policy and Grace," Beverly Santelli, Sarah N Robertson, Elizabeth K. Larson and Samia Humphrey surveyed 597 online students and 53 online faculty at a private, Southwestern university. This exploratory study found alignment between faculty and students on their perceptions of the effectiveness and fairness of an institutional late assignment policy and their perceptions of scenarios in which leniency is appropriate. Faculty and student perceptions differed in the need for strict faculty adherence to a late policy. Limitations and future research possibilities are discussed by the authors as well as implications for teaching.

Neuza Sofia Pedro and Swapna Kumar, in "Institutional Support for Online Teaching in Quality Assurance Frameworks," reviewed 13 online education quality frameworks to identify institutional services each framework included as being essential for quality higher education online teaching. They identified 18 components centered around the topics of: technologies and technical support; online program/course effectiveness or evaluation data; guidelines/standards for online course design; administrative and academic support for online students; professional development for faculty in online course development and teaching; instructional design and technical support; online program management support; online learning research support; and recognition for engagement in online learning. Their research highlights the faculty support components required to ensure quality online learning in higher education and is especially timely in the current focus on online learning.

Finally, in "Using Innovative and Scientifically-Based Debate to Build e-Learning Community," Cheng-Chia (Brian) Chen and Karen Swan present research that is very relevant to higher education's move to online learning due to COVID-19. They detail the experience of adjusting the synchronous debate of an on-campus course to asynchronous group debates in a fully online course on public health arguments and policies. Critical to this experience was the infusion of innovative pedagogical elements to facilitate an effective e-learning community. Surveys 
indicated that students were positive regarding the impact of the class debate on their active learning and critical thinking skills as well as their interaction and engagement with each other and the instructor. Furthermore, they were positive about the collaborative writing assignment's impact on their collaboration and learning. Comparisons between the online course and a comparable oncampus course found no significant difference in student perceptions, indicating that the online format did not diminish their perceptions of class experiences.

The editors of this special issue would like to acknowledge the OLC staff and numerous conference volunteers who always do an exceptional job but went above and beyond this year to make OLC Accelerate and OLC Innovate a success. The quick and unexpected pivot to a fully online conference resulted in more international attendees for OLC Innovate. We also are grateful to Sturdy Knight, managing editor, and Peter Shea, editor, of Online Learning, for their continuing guidance and help in continuing this focus on OLC Conference.

Finally, to our readers, we hope you find the research in this special focus on OLC conferences interesting and helpful. We invite you to consider submitting your research for presentation to OLC Accelerate in the fall, or OLC Innovate in the spring to share your lessons learned with others in the field. And, consider submitting your original research here to Online Learning in the future.

- Patsy D. Moskal, Director, Digital Learning Impact Evaluation, University of Central Florida; Patsy.Moskal@ucf.edu

- Laurie Dringus, Professor, College of Computing and Engineering, Nova Southeastern University; laurie@nova.edu

- Paige McDonald, Vice Chair, Clinical Research and Leadership Department, Assistant Professor of Clinical Research and Leadership, George Washington University School of Medicine and Health Sciences; paigem@gwu.edu

- Karen Swan, Stukel Professor of Educational Leadership, University of Illinois Springfield; kswan4@uis.edu 